\title{
Spinal Anesthesia for Removal of Thoraco-Lumbar Pedicle Screw
}

Nirmal Kumar Gyawali

\section{Authors Info:}

Dr. Nirmal Kumar Gyawali, Consultant Anesthesiologist, Western Hospital Nepalgunj

\section{Correspondance:}

Email/Contacts:

nkgyawali@gmail.com

081415277, 9858021961

\section{Disclaimer:}

\section{Conflict of Interest: None}

Source of Support: None

Copyright $\odot 2019$ by author(s),

licensed under the Creative

Commons Attribution International

License 4.0.

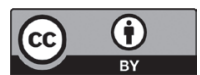

\section{ABSTRACT:}

Background: Spinal anesthesia compared to the general anesthesia has advantages of decreased blood loss, better cardiovascular stability and postoperative pain control. This study was designed to evaluate pedicle screw removal at lateral position under spinal anesthesia.

Methods: It is a prospective study done in patients with ASA (American Society of Anaesthesiologist) I and II with age between 17 to 75 years of both sex admitted for pedicle screw removal surgery during period March 2018 to April 2019 AD in Western Hospital and research centre Nepalgunj. All patients were informed about the risk of conversion to general anaesthesia in detail. Spinal anaesthesia was given to all 83 patients who came for pedicle screw removal.

Results: Out of all patients 54\% were from Hills and remaining 46\% were from Terai. The commonest cause of injury was fall from tree which was in $48(57.8 \%)$ out of 83 cases. Commonest level of injury was L1 followed by L2. Operation was completed under spinal anesthesia. None of the patient required conversion to general anaesthesia. 69 (83.1\%) patients did not require any additional medications whereas remaining $14(16.86 \%)$ needed additional medications. It allows good perioperative haemodynamic stability and also more cost effective.

Conclusion: Spinal anesthesia is safe and effective anesthetic technique for short duration spinal surgery as for example pedicle screw removal in terms perioperative events and in prolonged post-operative analgesia, as well as in terms of patient and surgeon's satisfaction.

Keywords: Spinal Anesthesia, Thoraco-lumbar Screw, Pedicle
Article Info

Received: October 15, 2019

Accepted: November 29, 2019

Published Online: December 10, 2019

How to cite this article in Vancouver Style?

Gyawali NK. Spinal Anesthesia for the Removal of the Thoracolumbar Pedicle Screw. Europasian J Med Sci 2019;1(1):35-39. https://doi.org/10.46405/ejms.v1i1.2
Access this article online

Publisher Note:

The Europasian Journal of Medical Sciences (EJMS) is an official Journal of Nirvana Psychosocial Care Center \& Ressearch Institute www.nirvanapscc.com. The Journal as well as publisher remain neutral with regards to any jurisdictional claims in any published articles, its contents and the institutional affiliations of the authors.
Quick Response (QR) Code

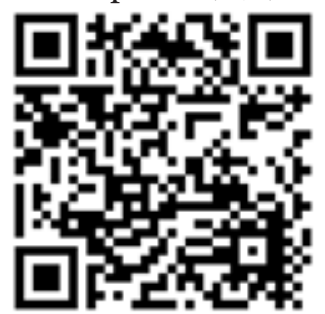

Scan Me for Full Text 


\section{INTRODUCTION}

Cinal anesthesia is a common mode of anesthesia for many surgical procedure of lower limb and lower abdominal surgeries done at Western Hospital Nepalgunj. Spinal anesthesia is achieved by injecting local anesthetic solution into the fluid surrounding the spinal cord. During spinal procedures some time combination of local anesthetic with opioid painkiller are injected into the cerebrospinal fluid of spinal cord. At our Hospital, we usually use only local anesthetic for spinal block.

Many new drugs are coming for spinal anesthesia because of unavailability of other drug. At our set up, heavy $(0.5 \%)$ bupivacaine is used for spinal anesthesia. Fracture of vertebra is the commonest trauma seen at western hospital for surgery. Common fracture sites are cervical, thoracic and lumbar but commonest site is lumbar vertebra. Operative procedures for vertebral fracture is fixation of vertebra with pedicle screw. Pedicle screw fixation or other spinal procedure can be done either under general or regional anesthesia. However, general anaesthesia is anesthetic technique of choice for prolonged surgeries performed in prone position. It is generally preferred due to patient's comfort and also to prevent airway compromise. Some studies suggest that all lumbar spine surgeries should be performed under general anaesthesia to guarantee better outcomes, while other studies show that short procedures like lumbar disectomy and removal of pedicle screw can be successfully done under spinal anesthesia with good outcomes and patient satisfaction. ${ }^{1}$

Regional anaesthesia is used for short simple procedures in carefully selected patients. Patients usually come for removal of pedicle after six month to one year. Removal of pedicle screw requires only half an hour time. As the procedure takes very short time, spinal anesthesia is anesthesia of choice for surgeon and anesthetics.

\section{MATERIALS AND METHODS}

This is a prospective study of cases admitted for pedicle screw removal during period of March 2018 to April 2019 AD (period of thirteen months). All the patients admitted for pedicle screw removal during the study period were included in the study. Patients with infection at the site of spinal injection, patients with bleeding disorder and uncooperative patients were excluded from the study.

Permission from Institutional ethical committee was obtained. All patients were explained about the study and written informed consent obtained. Preanaesthetic assessment was done to ascertain patient fitness and to rule out coagulopathy, hypovolaemia, infection at injection site, history of seizure and raised intracranial pressure. Routine investigations were requested and reviewed by the team. Fasting guidelines were also given. Monitor was attached after the patient was brought to the operation theatre. Routine monitoring of non-invasive blood pressure, oxygen saturation and electrocardiography was done throughout surgery and later in recovery room.

A 18 Gauge cannula was inserted, secured and patient preloaded with ringer's lactate 1 liter over 15 minutes. Patients were placed in lateral decubitus position. The subarachnoid space puncture was performed between $\mathrm{L}_{3}-\mathrm{L}_{4}$ apophyses and 3.5 to $4.0 \mathrm{ml}$ of hyperbaric $0.5 \%$ bupivacaine were injected. Afterwards patients were made to lie down supine for 10 to 15 minutes. Meanwhile an appropriate size catheter was placed aseptically into the urinary bladder. Once sensory block was confirmed at level $\mathrm{T}_{4}$ by painful and cold stimuli patient was again placed in lateral position and operation was started. If mean arterial pressure dropped below $60 \mathrm{~mm}$ of $\mathrm{Hg}$, $3 \mathrm{mg}$ of mephantaramine was administered.

Before procedure was started patient was given subcutaneous injection of local anaesthetic consisting of $1 \%$ xylocaine with adrenalin. After finishing operation patient was shifted to postoperative ward and maintained on IV fluids for four hours after surgery. Pain relief was maintained by intramuscular declofenec and injection paracetamol infusion intravenous. Oral feeding started 4 hours after surgery.

\section{RESULTS}

Total 83 patients had undergone pedicle screw removal during the study period. All procedures were completed under spinal anesthesia, with no cases 
needing conversion to general anesthesia. Age range of the patients was 16 to 55 years with $83 \%$ female and $17 \%$ male. The commonest level of injury was found to be L1 (50.6\% of cases).

\section{Demographic Characteristic}

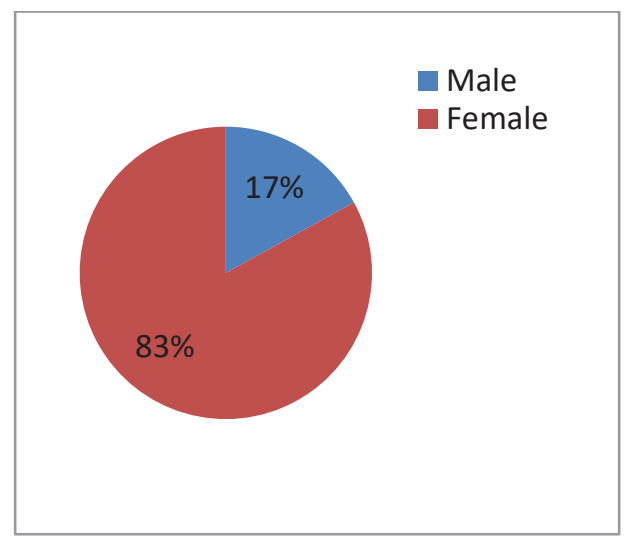

Figure 1: Pie chart showing sex of the patients

Out of total 83 patients, 14 (17\%) were male and 69 (83\%) were female. Male: Female ratio was 1:4.9 (fig. 1).

Age ranges of patients

\begin{tabular}{|l|l|l|}
\hline Age group (years) & Frequency & Percent (\%) \\
\hline $16-25$ & 24 & 28.3 \\
\hline $26-35$ & 29 & 34.9 \\
\hline $36-45$ & 16 & 19.3 \\
\hline $46-55$ & 7 & 8.4 \\
\hline $56-75$ & 7 & 8.4 \\
\hline
\end{tabular}

The maximum number of patients undergoing surgery were in age group 26-35 which was 29 (34.9\%) whereas seven patients in each age group 46-55 and 56-75.

The commonest Level of injury was found to be L1 in $42(50.6 \%)$ patients, followed by $\mathrm{L}_{2}$ in $19(22.9 \%)$ patients, $\mathrm{T}_{10}$ in $10(12 \%)$ patients. The least common level of injury were $\mathrm{T}_{9}, \mathrm{~T}_{10}, \mathrm{~L}_{4}$ and $\mathrm{T}_{11}-\mathrm{L}_{1}$ having only one patient in each level followed by $\mathrm{T}_{11}, \mathrm{~T}_{11^{-}{ }_{12}}$ having two patients in each level of injury out of 83 patients.
Fig 2: X-ray showing pedicle screw fixed in lumbar vertebra.

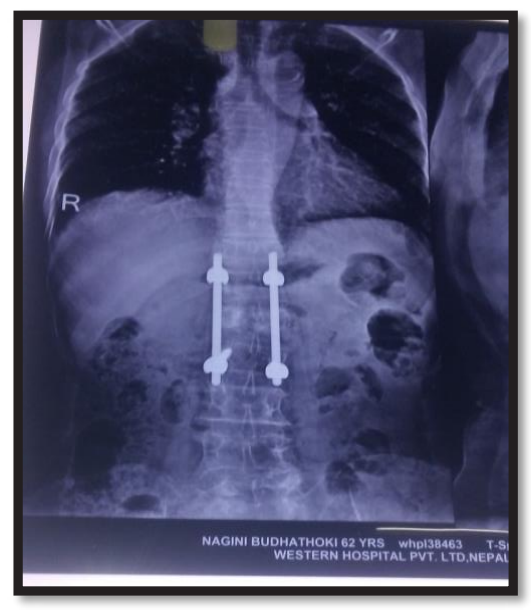

Fig 3: X-ray Showing pedicle screw fixed in thoracolumbar vertebra

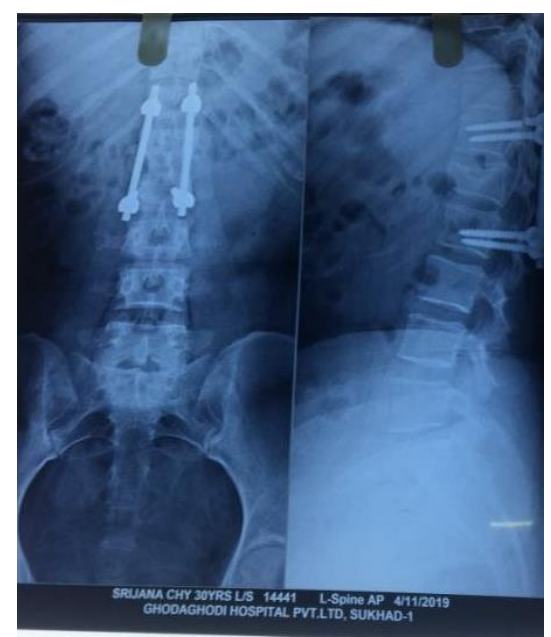

The figure 2 depicts pedicle screw fixation of L1 vertebra fracture. The X-ray film is of one year after fixation of pedicle screw, just before removal.

The figure 3 showed the X-ray film depicts T12 vertebral fracture with pedicle screw in-situ, lateral and AP view before removal.

All procedures were completed under spinal anesthesia, with no cases needing conversion to general anesthesia. Intraoperatively, two patients (2.4\%) presented with hypotention and mephanteramine was given. Out of 83 patients 69 patients $(83.1 \%)$ did not need any additional medication, 14 patients (16.86\%) experienced pain and received butorphanol and midazolam. 
There was no any complication except in 9 patients (10.84\%) who had postdural puncture headache and it was managed with intravenous paracetamol and bed rest.

\section{DISCUSSION}

This study shows that intrathecal administration of 3.5 to $4.0 \mathrm{ml}$ of $0.5 \%$ heavy bupivacaine was well tolerated and adequate block for spinal surgery of short duration was achieved. As in spinal anesthesia only one drug is used there is less chance of drug interaction and toxicity of drug. It is also cheaper option for poor patient of this area. Complication after anesthesia is very low, only one complication is post dural puncture headache which is only $10.84 \%$ in our study.

Single puncture spinal anesthesia can be an easier technique than general anesthesia. Monitoring of patients under spinal anesthesia is easier than general anesthesia. ${ }^{2}$ Complication of endotracheal intubation like damage to oral cavity, teeth, sore throat and aspiration, failure of intubation are absent in spinal anesthesia. The drugs and equipment required are much less and cheaper besides the length of hospital stay which is shorter. ${ }^{3}$ Taken together, less operative time suggest a faster turnover rate and more efficient use of the operation room. This suggests SA may be the more cost-effective method of anesthesia. Wang and co-worker in a randomized clinical trial in 60 women scheduled for lower abdominal surgery under general anesthesia or spinal anesthesia concluded that postoperative pain after lower abdominal surgery can be significantly decreased if the surgery is performed under spinal anesthesia with $3 \mathrm{ml}$ of hyperbaric $0.5 \%$ bupivacaine. ${ }^{4}$ The postoperative recovery of the patients was normal, it is described that spinal anesthesia is associated with lower frequency of serious postoperative morbidities and an improved outcome when compared to general anesthesia. ${ }^{5,6}$ Spinal anaesthesia is much safer for patients of respiratory diseases as Scott et al showed, pulmonary complications were more common in patients who underwent GA compared with regional anaesthesia. ${ }^{7}$

Two retrospective studies show that $S A$ resulted in better outcome compared with GA in patients underwent surgeries on lumber spine. ${ }^{8,9}$ Meng at el performed a systemic meta- analysis of eight randomized control trial of SA vs GA in lumbar spine surgery. They found those patients receiving SA had a reduction in intraoperative hypertension and tachycardia, reduced length of hospital stay, reduced PACU pain scores and reduced nausea and vomiting. ${ }^{10}$ McLain et al reported a case control study of 400 consecutive patients undergoing lumbar spine surgery in which SA was as safe and effective as GA and offered additional benefit, including less postoperative nausea, less need for analgesia, better perioperative haemodynamic, and shorter anesthesia time. ${ }^{11}$

In another study by Attari et al, 72 patients underwent spinal surgery with half assigned to general anesthesia and the other to spinal anesthesia. ${ }^{12}$ Statistically significant reduction in MAP and heart rate changes were noted in spinal group. In addition there was enhanced surgeon satisfaction as well as reduction in postoperative pain. These results were supported in another study which compared sixty patients undergoing lumber disk surgery. ${ }^{13,14}$ This group noted like Attari, that there were less episodes of tachycardia, hypertension and better postoperative pain with less nausea/vomiting in patients undergoing spinal.

\section{CONCLUSION}

Spinal anesthesia is safe and effective anesthetic technique for short duration spinal surgery as for example pedicle screw removal in terms perioperative events and in prolonged post-operative analgesia, as well as in terms of patient and surgeon's satisfaction.

\section{REFERERNCES}

1. Smrcka M, Baudysova O, Juran V, Vidlak M, Gal R, Smrcka V. Lumbar disc surgery in regional anaesthesia-40 years of experience. Acta Neurochir 2001 1;143(4):377-81. [GoogleScholar] [Full text]

2. Yuksek YN, Akat AZ, Gozalan U, Daglar G, Pala Y, Canturk M, et al. Laparoscopic cholecystectomy under spinal anesthsesia. Am J Surg. 2008;195(4):533-6. https://doi.org/10.1016/j. amjsurg.2007.05.043 [Googlescholar] [PMC] CrossRef Full text

3. Carlos C, Melvin E. First 300 cases of Pediatric Regional Anesthesia in Venezuela(Caudal,spinal and Peridural) The internet journal of Anesthesiology 2000;4:4-12. $\underline{\text { https://doi. }}$ org/10.5580/1c37 [GoogleScholar] [Full text] 
4. Mahaseth N, Khapung R, Budal B. Effect of Index of Conciousness (Ioc2) Monitoring on Remifentanil Dosage During Desflurane Anesthsia: A Randomized Trial. JKAHS 2019;2(1). https:// doi.org/10.3126/jkahs.v2i1.24390

5. Standl T, Eckert S, Schultem Esch J. Postoperative complains after spinal and thiopentone isofluraneanesthesia in patients undergoing orthopaedic surgery. Spinal versus general anesthesia. Acta Anaesthesiol Scand 1996;40(2):222-6. https://doi. org/10.1111/j.1399-6576.1996.tb04423.x $\quad \underline{P M C}$ CrossRef Full text

6. Rodger A, Walker N, Schug S, McKee A, Kehlet $\mathrm{H}$, van Zundert A et al. Reduction of postoperative morbidity and mortality with epidural or spinal anesthesia: Result from overview of randomized trials. BMJ 2000;321(7275):1493. https://doi. org/10.1136/bmj.321.7275.1493 [GoogleScholar] [PMC] [CrossRef] [Full text]

7. Scott NB, Kehlet H. Regional anaesthesia and surgical morbidity. Br J Surg 1988;75(4):299-304. Google Scholar] [PMC] [Full text]

8. Ditzler JW, Dumke PR, Harrington JJ, Fox JD. Should spinal anesthesia be used in surgery for herniated intervertebral disk. Anesth Analg 1959;38(2):118-24. https://doi. org/10.1213/00000539-195903000-00008 [GoogleScholar] [PMC] [CrossRef] [Full text]

9. Hassi N, Badaoui R, Cagny-Bellet A, Sifeddine

S, Ossart M. Spinal anesthesia for disk herniation and lumbar laminectomy. Apropos of 77 cases. Cah Anesthesiol 1995;43(1):21-5.https://doi. org/10.1111/anae.13702 [Google Scholar] [Full text
10. Meng T, Zhong Z, Meng L. Impact of spinal anesthesia VS. general anesthesia on perioperative out come in lumber spine surgery; a systemic review and meta analysis of randomized, controlled trial, Anesthesia 2017;72;391-401.https://doi. org/10.1111/anae.13702 [GoogleScholar] [PMC] CrossRef Full text

11. McLain RF, Bell GR, Kalfas I, Tetzlaff JE, Yoon HJ. Complication associated with lumbar laminectomy; a comparison of spinal versus general anesthesia. Spine (Phila Pa 1976.) 2004; 29:254. https://doi.org/10.1097/01. brs.0000144834.43115.38 [GoogleScholar] [PMC] [CrossRef] [Full text]

12. Atari MA, Mirhosseini SA, Honarmand A, Safavi MR. Spinal anesthesia versus general anesthesia for elective lumbar spine surgery; a randomized clinical trial. J Res Med Sci 2011;16:524-29. [GoogleScholar] [PMC] [Full text]

13. Kara I, Celik JB, Bahar OC. Comparision of spinal and general anesthesia in lumbar disc surgry. J Neuro Sci. 2011;28:487-96. [GoogleScholar]

14. Rijal E, Silwal S, Thapa S, Basnet S, Bhagat S. Nurses Knowledge on Management of Patient Receiving Spinal Anaesthesia in a Government Hospital. JKAHS [Internet]. 13Aug.2019 [cited 11Dec.2019];2(2). https://doi.org/10.3126/jkahs.

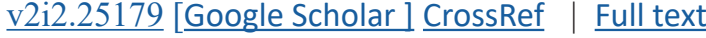

